\title{
Os gêneros textuais especializados e o conceito de comunidade discursiva como elementos de análise da variação denominativa em terminologia
}

\author{
Luís Henrique Serra" \\ Francisco Alves Filho**
}

\section{Resumo}

O texto apresenta um conjunto de reflexões acerca da relação entre a Terminologia e outros campos da Linguística e como essa relação pode colaborar para a ampliação da disciplina. São campos que colaboram na discussão a Linguística Textual e as Teorias dos Gêneros e do texto. No último campo, em especial, seria interessante um diálogo com os trabalhos de John Swales sobre a noção de comunidade discursiva. Parte-se do pressuposto que a análise de fenômenos estudados pela Terminologia pode ser feita a partir do diálogo da Terminologia com esses campos de conhecimento. As reflexões aqui apresentadas são feitas a partir da análise de um corpus diversificado com características que estão condicionadas à forma de comunicação dos especialistas de uma comunidade de especialista no setor da cana-de-açúcar. Os resultados mostram que muitos aspectos da variação terminológica podem ser entendidos a partir do tratamento de dados com reflexões teóricas do texto e do discurso presentes na Linguística.

Palavras-chave: Variação Terminológica; gêneros e textos especializados; comunidade discursiva.
Licenciado em Letras - Línguas Portuguesa e Inglesa e suas respectivas literaturas pela Universidade Federal do Maranhão (2012), mestre (2014) e doutor (2019) em Letras (Filologia e Língua Portuguesa) pela Universidade de São Paulo. É professor Adjunto da Universidade Federal do Maranhão, coordena o Grupo de Investigações do Ensino de Língua Portuguesa GIELP/UFMA/CNPq e é professor permanente do Programa de Pós-graduação em Letras - campus Bacabal (PGLB). Tem experiência na área de Lingüística, com ênfase em Lexicologia e Terminologia e ensino de língua portuguesa, Texto e Discurso, atuando principalmente nos seguintes temas: Linguística, léxico, texto oral e escrito, ensino de língua materna e estrangeira. E-mail: luis.ufma@gmail.com

** Possui graduação em Letras pela Universidade Federal do Piauí (1990), mestrado em Letras pela Universidade Federal de Pernambuco - UFPE-(2000) e doutorado em Lingüística pela Universidade Estadual de Campinas - UNICAMP - (2005). Desenvolveu projeto de pós-doutorado na UNICAMP (2009-2010). Atualmente é professor Associado da Universidade Federal do Piauí, Coordena o Núcleo de Pesquisa CATAPHORA, através do qual coordena uma pesquisa, com financiamento do CNPQ, sobre letramento acadêmico com foco na escrita de projetos de pesquisa. É membro do comitê de Assessoramento Técnico-Científico do PIBIC/UFPI e do comitê de Pós-Graduação (UFPI). Foi subcoordenador do GT/ANPOLL de Linguistica de Texto e Análise da Conversação (2010-2012). Atualmente é membro efetivo do GT/ANPOLL Gêneros Textuais e Discursivos. Publicou o livro Gêneros Jornalísticos: Notícias e Carta de Leitor no Ensino Fundamental, pela Editora Cortez e coautorou a coleção de livros didáticos Projeto Carnaúba, voltada para ensino de leitura e produção de textos no Ensino Fundamental.Tem experiência na área de Lingüística, com ênfase em Teorias de Texto, Análise de Gêneros, Gêneros Acadêmicos e Escrita científica. Atualmente é coordenador do Programa de Pós-graduação em Letras na UFPI. E-mail chicofilhoo@ gmail.com

Data de submissão: abr. 2021 - Data de aceite: jul. 2021

http://dx.doi.org/10.5335/rdes.v17i2.12613 
Um trabalho que visa reconhecer os usos da linguagem de uma ciência em suas diferentes facetas e instâncias, ultrapassando o estudo de terminologias, ainda é/ seria um trabalho de/em Terminologia ou se seria um estudo de textos a partir de corpora em sentido amplo? (...) quem não

se centra em reconhecer terminologias como o objetivo de produzir glossários ou outro repertório ainda é um terminólogo? Essa, podem dizer, é apenas uma questão de identidade, que pode ser mais ou menos importante, dependendo do ponto de vista de quem a julgue, claro.

(FINATTO E AZEREDO, 2013, p. 562)

\section{Introdução}

A Terminologia é uma disciplina que vem se modificando muito nos últimos anos, graças às contribuições que tem recebido de diferentes campos do saber humano, principalmente da Linguística, em seus diferentes enfoques teóricos e metodológicos. São exemplos de campos da Linguística que têm contribuído com o cabedal teórico da Terminologia, a Linguística de Corpus, a Linguística Textual, a Sociolinguística e as discussões sobre os gêneros textuais e discursivos. Estes últimos, muito embora não sejam um campo teórico coeso, mais sim, um conjunto de abordagens feitas por diferentes estudiosos nas diferentes áreas da Linguística, sobretudo aquelas que veem a língua em funcionamento e em contextos de uso, têm sido uma alternativa para a ampliação das perspectivas e para as análises do discurso especializado.
Muito embora receba esse grande número de contribuições, nos trabalhos produzidos em língua portuguesa, ainda são escassos os estudos que se interessam por aspectos que são relevantes para a compreensão das linguagens especializadas, entendidas aqui como um conjunto de elementos semióticos que produzem sentido nos universos especializados e que são elementos que permeiam a comunicação entre especialistas de diferentes graus de conhecimento, além de especialistas em formação e o público leigo. São aspectos relevantes da comunicação especializada o texto, o contexto, os gêneros textuais e o enunciado especializado, só para ficar em alguns exemplos de elementos que compõem a comunicação especializada e que ainda são pouco explorados pelos pesquisadores no campo da Terminologia. É nesse sentido que Finatto e Azeredo (2010, p. 560) explicam que

[...] descrever qualquer linguagem técnica ou científica implica descrever seus diferentes usos, sobretudo os usos textuais, em diferentes situações. Dessa forma, além do texto em si, há todo um entorno de significação que precisa ser considerado quando se pretende descrever os usos de uma linguagem científica.

Outro ponto importante para a Terminologia e que tem sido discutido desde sua concepção como disciplina é a variação terminológica, seja ela denominativa ou conceitual. Ponto crucial para mudanças importantes dentro do campo 
da Terminologia, "hoje em dia, a variação dos termos é um fenômeno aceito e, de fato, é uma premissa básica já estabelecida para a investigação terminológica ${ }^{1}$." (FREIXA, 2013, p. 38). A partir dessas ideias, muitos são os trabalhos que têm buscado demonstrar que a comunicação especializada é permeada por variação e que esse é um mecanismo importante para a comunicação, visto que ela permite a atualização do discurso especializado para diferentes instâncias e níveis de público especializado. No entanto, grande parte dos trabalhos na área ainda se ocupam de ver o aspecto estritamente linguístico (formal), deixando de fora aspectos do uso e do funcionamento da linguagem, em outras palavras, os trabalhos no campo da Terminologia têm, em sua grande maioria, focado no produto e não no processo comunicativo. Desse modo, é importante ver a variação denominativa dentro de um processo comunicativo real e os estudos sobre enunciação e gêneros textuais apresentam elementos importantes.

Cumpre pontuar que, entende-se por variação denominativa a característica de uma unidade de conhecimento especializada reconhecida e compartilhada por uma comunidade de especialistas de um domínio especializado (conceito) apresentar duas ou mais denominações em um ou mais contextos comunicativos próprios dessa comunidade; em outras palavras, um conjunto de elementos linguísticos ou de denominações, sejam linguísticas, numéricas ou braquigráficas, que representam um conceito dentro de um texto, seja oral ou escrito.

Nesse sentido, este estudo busca apresentar algumas reflexões e caminhos para que esses elementos possam fazer parte do conjunto de preocupações que a Terminologia tem e que são importantes para a compreensão da comunicação em ambiente especializado. $\mathrm{O}$ presente texto foca nos gêneros textuais como elementos que organizam o discurso especializado, e, nesse sentido, busca subsídios nas teorias do gênero que visam ao funcionamento e a construção de sentido a partir do uso, como a teoria do gênero de Bakhtin (2018) e dos gêneros em ambientes acadêmicos e comunidade discursiva, de Swales (1990, 2016). No âmbito da Terminologia, discute-se também a variação terminológica e como aspectos contextuais e comunicativos dos universos discursivos especializados colaboram para essa variação ou como ambos os aspectos estão interligados.

Nesse sentido, o texto apresenta exemplos do universo discursivo da cana-de-açúcar, com gêneros especializados com diferentes níveis de especialização e os analisa buscando compreender o papel dos aspectos funcionais ou contextuais desse universo para a variação denominativa encontrada em diferentes gêneros textuais do universo especializado. $\mathrm{O}$ trabalho, portanto, analisa a variação 
denominativa considerando aspectos do uso dos gêneros e do discurso especializados.

\section{Terminologia descritivista: gêneros textuais e a comunidade discursiva}

Desde seu início, a Terminologia vem discutindo a importância de reconhecer ou não sua importância para a comunicação entre especialistas da mesma ou de diferentes nacionalidades. Essa discussão, capitaneado por Wüster (1998) e por outros tantos que discutiam a pertinência dessa ideia, sua abrangência e aplicação, faz com que a Terminologia se desenvolva como disciplina teórica, trazendo para o escopo da disciplina um número variado de questões que visam à descrição ou à normatização da comunicação científica e técnica no mundo. Dessas discussões, nascem produtos teóricos como o que ficou conhecida como Teoria Geral da Terminologia (WÜSTER, 1998; FELBER 1984, 1985) e a Teoria Comunicativa da Terminologia (CABRÉ, 1998, 2003) e as inúmeras abordagens que têm esses dois pilares teóricos como norte.

No primeiro grupo de discussões, a Terminologia é encarada como uma organizadora do conhecimento entre outras funções mais práticas, conforme explica Felber (1983, p. 3),
Terminologias, como agregadoras de termos, que representam o sistema de conceitos de vários campos de conhecimento, são as ferramentas muito importantes para: 1 . Sistematizar o conhecimento (esse é, classificação conceitual de cada campo de conhecimento). 2. Transferir conhecimento, habilidades e tecnologias. 3. Traduzir textos científicos. 4 . Formular informações sobre um tema. 5. Recuperar informações armazenadas (linguagem documental, tesauros e classificações) ${ }^{2}$.

Cabré (1999, p. 45), por seu turno, vê a Terminologia a partir de um outro ângulo, muito mais como parte do complexo sistema de linguagem natural do que uma ferramenta, como defende Felber. Para ela, a "Terminologia pode fazer parte dos signos da linguagem natural e integrar-se ao conhecimento do falante, que é, ao mesmo tempo, falante de uma língua e especialista de uma matéria."3

Esse novo olhar sobre as unidades do léxico especializado trouxe um conjunto de novas reflexões e abordagens que ampliaram o interesse da Terminologia. Ao longo da história da Terminologia, Cabré (1998) identifica 4 momentos da história desse campo de reflexões teóricas e metodológicas: (i) o início; (ii) a estruturação do campo; (iii) a sistematização e (iv) a expansão. A autora identifica o período de 1985 até $o$ período atual como o momento de expansão das ideias das concepções terminológicas.

O contraponto de pontos de vistas com relação ao objeto de análise da Terminologia fundamenta duas grandes vertentes de estudos e de tratamento de dados que ficaram conhecidas como abordagem 
prescritivista - que se fundamenta nas ideias de Wüster (1998) e seus seguidores - e abordagem descritivista - baseada nas ideias de uma diversidade de linguistas, dentre eles Cabré (1998), Hoffman (1998), Gaudin (1993) e seus seguidores.

$\mathrm{Na}$ abordagem descritivista, têm surgido novos enfoques terminológicos que se voltam para o texto e para a complexidade do fenômeno comunicativo. Nesse sentido, embora recentes, existem novas discussões sobre o estatuto das linguagens especializadas e da comunicação em ambientes especializados e o conceito de comunidade discursiva e de gênero textual. Nessas discussões, esses elementos são importantes para a compreensão da comunicação especializada.

Uma das primeiras e representativas discussões são as apresentadas pela Terminologia Textual ${ }^{4}$, que é um campo de abordagem dos estudos terminológicos que olha o texto especializado como um dos elementos importantes para a compreensão dos fenômenos linguísticos e comunicativos no âmbito especializado (CIAPUSCIO, 1998, 2003). Hoffman, outra grande e importante nome desse campo, entende, assim como na linguagem corrente, no contexto especializado, “(...) o texto é o signo linguístico primário, isto é, sob condições normais, a linguagem se realiza apenas por meio de textos". (HOFFMAN, 2015, p. 47). Kocoureck (1991, p 71), no mesmo sentido, entende que os textos especializados
(...) apreendem e expressam o conteúdo especializado, nos quais as unidades semânticas dominantes são os termos. O termo é uma unidade lexical - ou sua acepção definida nos textos especializados, em que suas ocorrências aparecem integradas na tessitura do texto ${ }^{5}$.

Esses autores demonstram a importância do texto e do seu uso para muitas das concepções dentro da Terminologia. Com o olhar centrado no texto, a Terminologia precisaria ampliar ainda mais a sua relação com ele, e aí que as teorias do discurso e do texto são peça fundamental para a ampliação do escopo teórico da Terminologia moderna. Cabré (1998, p. 123), quando lança os fundamentos de uma teoria terminológica que considera o aspecto comunicativo do termo, explica que o termo é ativado em uma unidade léxica dependendo do contexto pragmático em que essa unidade é utilizada. Nas palavras da autora, "o caráter de um termo é ativado em função de seu uso no contexto e situação adequados. ${ }^{6}$ "

Nesse sentido, a partir de Bakhtin (2016), é importante assumir que toda e qualquer atividade dos diferentes ramos do pensar e do fazer humano estão ligados à linguagem e que esse fazer é múltiplo e cada elemento é dotado de uma multiplicidade de elementos comunicativos com os quis a língua é empregada de diferentes formas, cumprindo diferentes objetivos. Ainda de acordo com esse autor, a comunicação é vista num amplo conjunto de elementos que vão 
muito além do formalista, cobrindo o uso e a construção de sentidos singulares nos diferentes contextos comunicativos. A relação entre esses elementos, indispensável para a comunicação em qualquer ambiente comunicativo, articula-se a partir das especificidades de cada campo e colabora para uma cultura comunicativa nos âmbitos do fazer humano. É a partir dessa reflexão que se pode pensar nos gêneros do discurso especializado. Sobretudo porque “(...) cada campo de utilização da língua elabora seus tipos relativamente estáveis de enunciados (...)." (BAKHTIN, 2016, p. 12, grifos originais) e os diferentes âmbitos de um universo especializado também organizam os próprios gêneros textuais a partir das necessidades comunicativas existentes.

Também é importante atentar para o dizer de Hoffman (1998) quando lança luz sobre os diferentes contextos comunicativos dentro dos universos especializados. Muito embora, nesse momento, o autor não utilize o termo gênero, existe uma coincidência entre o conceito bakhtiniano de gêneros do discurso e a concepção de Hoffman (1998, p. 112) sobre os usos linguísticos nos universos especializados:

Assim, parece que a coincidência no uso de certos recursos linguísticos e na semelhança da função comunicativa fornece uma base para a classificação de textos especializados. Essa suposição é reforçada pela diferenciação mais ou menos intuitiva e prática de tipos de texto, como um livro, trabalho de referência, ativo, revisão, relatório, crítica, carta comercial etc. ${ }^{7}$
A capacidade intuitiva de se comunicar que todo falante tem nos diferentes contextos comunicativos - especializados ou não - faz com que os falantes sigam um modelo relativamente estável de uso da linguagem e produzam um número infinito de gêneros que caracterizam e classificam determinados campos especializados. Nesse sentido, não se pode pensar que apenas a presença de unidades especializadas de determinados domínios especializado em um texto é suficiente para caracterizar o texto como especializado, mas além disso, seu contexto de uso/produção, quem escreve e a finalidade do texto.

Nesse sentido, para pensarmos em texto e gêneros especializados, é necessário antes admitir a existência de um universo especializado. Embora pouco problematizado, o conceito de universo especializado pode ser entendido como uma comunidade de especialistas que relacionam saberes sobre uma temática do saber ou fazer humana. Swales oferece alguns elementos para a melhor compreensão desse conceito por meio de suas pesquisas para a constituição do que ele chama de Comunidade Discursiva (SWALES, 1990, 2016).

$\mathrm{O}$ autor buscou entender os valores sociais e comunicativos de uma comunidade de especialistas e a cultura de um grupo de indivíduos que têm em comum o conhecimento sobre um tema; em outros termos, como um conjunto de indiví- 
duos que tem objetivos afins concretiza linguisticamente a comunidade em que está inserido? É importante atentar que essa comunidade se comunica constantemente, usa mecanismos ou situações comunicativas próprias que geram gêneros diversificados para promover a comunicação entre os indivíduos pertencentes ao grupo. Outra característica interessante no conceito de Swales - e a que mais importa para a Terminologia é que essa comunidade se utiliza de um léxico específico, reconhecido por grupos de membros com nível de conhecimento diferenciado (ingressantes e especialistas na área). Hans e Biasi-Rodrigues (2005, p. 115) explicam que

A noção de comunidade discursiva é empregada em relação ao ensino de produção de textos como uma atividade social, realizada por comunidades que têm conversões específicas e para os quais o discurso faz parte de seu comportamento social.

As autoras explicam ainda que esse conjunto de elementos que caracterizam as comunidades discursivas são o que os indivíduos que ingressam em uma determinada área (em um curso de graduação ou no estágio, por exemplo) devem aprender para ser considerados participantes dessa comunidade.

Assim como um universo especializado, a ideia da comunidade discursiva dá elementos para a análise do funcionamento do gênero em um universo especializado, identificando sua comple- xidade e sua função social e a cultura comunicativa das diferentes áreas do saber humano. Com base nisso, é importante e possível analisar os diferentes atos comunicativos de uma comunidade discursiva/universo especializado a partir de um aporte teórico que vise o texto e o discurso especializado como um objeto interessante, que considere o texto/discurso especializado para além do que a presença ou não de termos científicos.

Nesse sentido, é importante atentar que a variação denominativa em um texto tem suas finalidades. A grande importância da questão da variação denominativa está relacionada com aspectos do próprio texto (estrutura, finalidade e público-alvo). Krieger e Finatto (2016, p. 107) explicam que "os termos sofrem os efeitos de todos os mecanismos sintagmáticos e pragmáticos das cadeias discursivas que dão suporte à comunicação especializada”. Desse modo, parte-se do pressuposto de que um dos caminhos importantes (mas não o único) para os estudos terminológico voltados para a questão do gênero e do texto especializado é entender qual a finalidade da variação denominativa no texto especializado. Para essa finalidade, pode-se receber grande contribuição da Linguística Textual e das demais teorias do texto e dos gêneros textuais. 
A variação terminológica no universo canavieiro:

\section{um olhar para diferentes gêneros especializados}

Buscando observar a variação terminológica denominativa em um conjunto de gêneros textuais recorrentes no universo canavieiro do Brasil, foi selecionado um conjunto de textos com características de uso e função diferentes dentro da comunidade discursiva dos engenheiros agrônomos especialistas em cana-de-açúcar. Os textos foram produzidos por especialistas com alto grau de escolaridade (doutores com muitos anos de experiência o setor canavieiro. As informações sobre os autores foram coletadas na plataforma Lattes e nos sites dos Programas de Pós-graduação aos quais os autores estariam associados), relacionamento e reconhecimento dentro da comunidade discursiva da engenharia agronômica no Brasil e fora dela. Os textos têm materialização diferentes: oral e escrita. A pesquisa também selecionou textos desses especialistas em diferentes contextos comunicativos especializados com diferentes níveis de especialização, ou seja, textos didáticos, de divulgação e especializados.

Considerando esses aspectos, foram selecionados, para exemplo neste texto, dois gêneros de textos considerados prototípicos dessa comunidade: o artigo científico e a conferência. A conferência foi selecionada porque, além de ser um texto oral, a sua prática é muito recorrente na comunidade em foco. $\mathrm{Na}$ comunidade dos engenheiros agrônomos da cana-de-açúcar, são muito recorrentes os eventos técnicos em que engenheiros agrônomos se reúnem por uma semana para fazer cursos e painéis com economistas, cientistas e observadores do setor para discutir os caminhos e desenvolvimentos do setor. Embora esse tipo de evento não tenha um caráter estritamente acadêmico, especialistas professores universitários também palestram buscando apresentar pesquisas e métodos novos de tratamento da cultura da cana-de-açúcar.

Cumpre informar que, nessa comunidade, os eventos são altamente restritivos às pessoas que têm formação ou que trabalham no setor canavieiro, sendo exigido, no momento da inscrição, documentos que comprovem a formação na área ou atuação no setor. São poucos os estudantes presentes nesses eventos, principalmente por conta de fatores econômicos, uma vez que os valores exigidos para participar desse tipo de evento são muito elevados. $O$ evento de que se trata aqui não é um evento acadêmico, esses são geralmente realizados pelos cursos das universidades e com valores mais acessíveis e a presença de pesquisas acadêmicas é maior. Esse último tipo de evento (eventos produzidos pela universidade), é curioso notar, é um 
tipo de evento mais raro nessa comunidade. Os encontros da comunidade ocorrem em forma de feiras e ou workshops, em que além de apresentação de pesquisas e descobertas dos especialistas, cursos de formação e reuniões de negócios acontecem com muita frequência.

$\mathrm{O}$ artigo científico é o outro gênero selecionado porque muitas das palestras desses eventos transformam-se em artigos científicos publicados em revistas acadêmicas do setor, e esse é o tipo de artigo mais utilizado pelos especialistas para publicarem suas descobertas. É interessante observar que a maioria dos artigos publicados por esses pesquisadores foram escritos em língua inglesa, sendo que os textos raramente estão em língua portuguesa. Esse fato revela-se a partir de uma intenção de internacionalização do setor, visto que o produto e as descobertas de técnicas e pesquisas são comumente feitas com especialistas de empresas e universidades internacionais. Anais de evento e livros digitais são raros nessa comunidade, e mais raro ainda são textos escritos em português e disponíveis gratuitamente online.

Considerando esses critérios e as características dessa comunidade discursiva, depois de longas horas nos motores de busca do Google, foi possível construir um corpus de tamanho razoável para as discussões aqui apresentadas. No corpus desta pesquisa, foram selecionados 41 artigos e 11 conferências. Essa quantidade de textos foi organizada após numerosas buscas na internet, visto que, como explicado, a produção e o acesso a trabalhos disponíveis em língua portuguesa e gratuitamente são raros. Como já foi afirmado, os textos foram coletados na plataforma Google.

Embora o número de exemplares de gêneros seja pequeno, quando se considera o número de unidades lexicais desses gêneros, tem-se um número razoável de palavras para analisar, e isso foi possível fazer com a colaboração das ideias e ferramentas da Linguística de Corpus. É importante destacar que a pesquisa terminológica que considere um grande número de dados lexicais tem contado com o apoio da Linguística de Corpus para o seu desenvolvimento. Nesse sentido, de acordo com Finatto (2004), o diálogo entre a Terminologia e a Linguística de Corpus tem sido muito frutífero e tem colaborado para novas perspectivas nos estudos terminológicos. A autora entende que a colaboração da Linguística de Corpus para a Terminologia vem das inúmeras possibilidades que aquele campo de estudos possibilita para a análise da linguagem:

A Linguística de Corpus, dito de um modo muito simples, parte do pressuposto de que é preciso observar usos extensivos de língua para que deles se depreendam sistematicidades, especificidades, descrições e explicações sobre gramática, léxico, sobre configuração e perfis de práticas textuais. (FINATTO, 2004, p. 98)

Ainda sobre a relação entre Terminologia e Linguística de Corpus, a autora 
explica que "Terminologia e Lingüística de Corpus têm dialogado em torno de um objeto comum, o texto técnico-científico e seu léxico, os quais são objeto de exploração com apoio informatizado." (op cit). Considerando esse diálogo, foi construído um conjunto de corpora em que diferentes textos especializados puderam ser observados a partir de sua terminologia. Considerando o conceito de comunidade discursiva de Swales, foram coletados na internet, na rede social Youtube da Multinacional Google, textos orais em que especialistas em cana-de-açúcar comunicavam-se em diferentes contextos especializados (conferência, aula e programa de TV). Os textos escritos utilizados neste estudo foram coletados no site de buscas de conteúdo da Google (comum e acadêmico), principalmente em sites de revista acadêmica e revistas de divulgação científica, além de material didático de cursos de educação a distância na área da engenharia agronômica, da disciplina cana-de-açúcar.

Por meio do suíte de programas de ferramentas de processamento da linguagem Antcont, foi possível fazer uma averiguação da variação denominativa existente nos textos dos artigos e nas transcrições das conferências coletadas. O corpus de análise neste estudo é constituído por um total de 139.921 palavras (tokens). A seguir, um quadro com uma divisão das características do corpus.
Quadro 1 - Números do corpus

\begin{tabular}{|l|r|}
\hline \multicolumn{2}{|c|}{ CORPORA } \\
\hline Total de textos orais & 41 \\
\hline Total de Textos Escritos & 32.5599 \\
\hline $\begin{array}{l}\text { Total de palavras (token) no } \\
\text { corpus escrito }\end{array}$ & 107.310 \\
\hline $\begin{array}{l}\text { Total de palavras (token) no } \\
\text { corpus oral }\end{array}$ & 139.921 \\
\hline Total de Tokens no corpus
\end{tabular}

Fonte: elaborado pelo autor.

Para a análise da variação denominativa terminológica no corpus, foram selecionados 20 conceitos (aqui entendida como uma unidade de conhecimento reconhecida pela comunidade de especialistas e registrada no corpus e em dicionários especializados da área, sendo possível observar sua existência por meio das denominações e das definições de dicionários especializados). Os conceitos são do campo conceitual plantação, por ser um campo produtivo e importante na indústria da cana-de-açúcar, sobretudo porque o lucro do setor depende muito dessa fase de produção, por isso são investidas grandes somas de dinheiro para pesquisa e para a tecnologia. Por meio do programa Antconc, foi feita uma busca no corpus oral e escrito e foi observada a variação denominativa dos 20 conceitos no corpus selecionado.

\section{A variação denominativa terminológica: olhando para o (con)texto}

Os quadros a seguir exemplificam a variação denominativa encontrada 
no corpus. Por se tratar de uma ilustração, selecionamos a amostra de apenas 4 conceitos nos textos orais e escritos:

Quadro 2 - A variação denominativa no gênero Artigo Científico

\begin{tabular}{|c|c|c|}
\hline \multicolumn{3}{|c|}{ Corpora escrito - Gênero Artigo Científico } \\
\hline Definição do conceito & Termo mais recorrente & Variantes \\
\hline $\begin{array}{l}\text { Tronco da planta da cana- } \\
\text { de-açúcar }\end{array}$ & Colmo & Colmo de cana-de-açúcar \\
\hline $\begin{array}{l}\text { Espaço entre as linhas de } \\
\text { cana no canavial }\end{array}$ & Entrelinhas & $\begin{array}{l}\text { Entrelinhas de plantio, espaçamento, } \\
\text { espaçamento entre linhas.... }\end{array}$ \\
\hline Fileira de cana no canavial & Linha & $\begin{array}{l}\text { Linhas de cultura da cana-de-açúcar, } \\
\text { linha de cana, fileira, linha de cana... }\end{array}$ \\
\hline $\begin{array}{l}\text { A cana que fica no canavial } \\
\text { após o corte }\end{array}$ & Cana-soca & Soca, rebrota da soqueira, rebrota \\
\hline
\end{tabular}

Fonte: elaborado pelo autor.

Quadro 3 - A variação denominativa no gênero Conferência

\begin{tabular}{|l|l|l|}
\hline \multicolumn{2}{|c|}{ Corpus oral - Gênero Conferência } \\
\hline \multicolumn{1}{|c|}{ Definição do conceito } & Termo mais recorrente & \multicolumn{1}{c|}{ Variantes } \\
\hline Tronco da planta da cana-de-açúcar & Colmo & \\
\hline Espaço entre as linhas de cana no canavial & Entrelinha & Espaçamento \\
\hline Fileira de cana no canavial & Linha & Leira \\
\hline A cana que fica no canavial após o corte & Cana-soca & \\
\hline
\end{tabular}

Fonte: elaborado pelo autor.

Como é possível observar em uma rápida leitura dos quadros 3 e 4 , a variação denominativa nos dois gêneros ilustrados é diferente, e essa é recorrente em todos os quadros produzidos para o estudo. Um cálculo de média simples em todo o corpus mostra que a média de variação (ou seja, a razão entre o número de conceito para o número de variantes (FREIXA, 2002)) é maior no texto escrito $(3,6)$ do que no corpus oral $(2,0)$. Uma primeira hipótese que aponta para essa questão poderia ser o fato de, no corpus selecionado, a quantidade de texto escrito ser maior do que de texto oral. Tentando resolver essa questão, foi feita uma segunda amostra, com o número de 10 mil tokens nas amostras dos gêneros dos dois modos (oral e escrito), e foi possível observar que o resultado se repete, mostrando que a quantidade é relevante, mas não muda a configuração dos resultados (cf. SERRA, 2019).

Com esses resultados, foi necessário entender essa amostra de variação a partir de conceitos menos gerais, olhando mais para aspectos do texto e do gênero especializado. O primeiro ponto observado é que, conforme Koch (2015), a densidade lexical, ou seja, a quantidade de 
palavras necessária para a organização do texto, no texto oral é muito menor do que a do texto escrito, e isso se dá porque este é mais dependente da descrição do que aquele, que é mais contextualizado e recorre a elementos não-linguísticos para construir sentido. Um outro ponto é que os termos dos textos orais são mais simples e formados por elementos monolexicais (sintagmas nominais com apenas um elemento léxico), enquanto, nos gêneros escritos, os textos são mais complexos e requerem outros elementos para sua estruturação, além de serem mais descritivos, ou seja, menos lexicalizados do que os da oralidade, que opta pela simplicidade e termos mais cristalizados. A explicação que se levanta é de que o texto oral no gênero palestra para especialistas é mais dinâmico e permite menos reformulações antes de atingir o público-alvo, diferente da escrita em que o autor do texto pode reformular várias vezes o seu texto antes mesmo que ele chegue a seu interlocutor. Dessa forma, no texto oral, o falante deve recorrer a unidades lexicais mais específicas e que caracterizam o discurso dessa área, sobretudo porque o público-alvo a quem se destina é de especialistas, muito embora de diferentes graus de conhecimento (estudantes e especialistas).

Considerando ainda que a variação denominativa tem uma função dentro do texto especializado e que essa funcionalidade está relacionada a um gênero de discurso, à materialidade e ao contexto de uso, foram selecionados dois gêneros (um da oralidade e o outro da escrita) para que se observe como essa variação se apresenta no texto e como ela colabora para a coesão dele. Foram selecionados dois trechos, um de um artigo científico (art 1) e o outro de uma transcrição de uma das palestras da amostra (pale 1) para mostrar como as diferentes denominações se organizam no texto, respeitando suas especificidades (canal, gênero...).

Nos trechos a seguir, são apresentadas algumas estratégias de referenciação (ou seja, de relação de informações no texto) e de organização textual nos diferentes gêneros textuais dos corpora deste estudo. Nos trechos, é interessante evidenciar a variação denominativa como aspecto organizador para, mais uma vez, demonstrar a proximidade entre a linguagem cotidiana e a especializada. Os trechos são relativos ao conceito denominado a partir dos elementos canavial e cana-soca. As palavras negritadas são os elementos de uma rede de pontos conceituais que colabora para a coesão do texto. Processos de progressão e de referenciação são executados por meio dessa rede.

Evitar áreas infestadas por cupins subterrâneos, já que são de difícil controle e prejudicam seriamente a germinação, produção e longevidade do canavial, causando danos aos toletes utilizados no plantio e ao sistema radicular das plantas. Visando diminuir 
os gastos com mão-de-obra no transporte, o canavial deve ficar situado próximo ao local de fornecimento de forragem aos animais (curral), o que também facilita a coleta do esterco para adubação. A área a ser cultivada depende dentre outros fatores, da produtividade esperada, do número e consumo diário dos animais a serem suplementados, e do período de fornecimento. Como indicativo, considerando-se que o fornecimento de aproximadamente $25 \mathrm{~kg}$ de cana triturada / vaca / dia, supra adequadamente as necessidades nutricionais dos animais; um canavial bem manejado pode atingir cerca de 80 toneladas de matéria verde / ha / ano; o período de fornecimento seja de 120 dias, junho a setembro, meses de maior déficit hídrico em Rondônia, e consequentemente na disponibilidade de forragem das pastagens; espera-se que um hectare de cana-de-açúcar possa atender até 27 vacas. Prolongando-se o fornecimento para 150 dias, 21 vacas serão supridas. Com base nessas estimativas, é definida a área a ser cultivada, sempre mantendo uma margem de segurança, como precaução a períodos de maior adversidade à cultura. (Art 1)

Como é possível observar no trecho apresentado, a rede de elementos colabora para que o texto se estruture de modo que a leitura possa ser fluida e clara. Nesse sentido, o encadeamento desses itens se dá por um processo de associação, que é produzido a partir de uma rede conceitual que tem como núcleo o conceito de canavial, que recebe outras denominações lexicalizadas e em processo de lexicalização. Desse modo, a variação denominativa, que se evidencia por meio das denominações área, área $a$ ser cultivada e hectare de cana-de-açúcar, permite a construção da coesão e da coerência do texto especializado e mostram a amplitude desse conceito, assim como sua relevância para a indústria. A partir dessa variação de denominações, mesmo quem não é um especialista, pode inferir que se está falando de uma área com grandes proporções e que serve para o cultivo de cana-de-açúcar, graças aos traços evidenciados nas expressões referenciais que designam o conceito nesse texto, embora pareça que essa não seja a preocupação principal dos especialistas assinantes do texto. Essa comunidade de especialistas entende que o bom cultivo e tratamento desse espaço é primordial para o sucesso da produção, e isso fica evidente porque os textos dos artigos científicos dessa comunidade caracterizam-se por uma tipologia descritiva e constantes divulgação de outras pesquisas feitas no Brasil e fora dele. Essa prática revela um modo de usos da linguagem de uma comunidade e que constrói a identidade de uma comunidade de especialistas.

De acordo com Biasi-Rodrigues, Araújo e Sousa (2009, p. 31),

A noção de comunidade discursiva, especialmente, evoluiu para a caracterização de um grupo de pessoas que trabalham no mesmo lugar e mantêm um repertório de gêneros, que possuem traços retóricos claros e validam as atividades da comunidade.

É importante destacar que, muito embora Swales (2016) tenha revisto algumas colocações sobre essa noção, 
destacando e acrescentando aspectos mais práticos e pragmáticos ao conceito (existem várias comunidades discursivas, com diferentes objetivos, que podem ser locais, internacionais e que perpassam diferentes práticas e gêneros, entre outras reformulações mais pontuais), a ideia principal, de que um conjunto de especialistas se reúne em uma comunidade, se mantém.

A estrutura conceitual do conceito denominado por cana-soca também se revela por meio da organização do texto, visto que, em tela, as diferentes denominações do conceito estão quase todas no início de cada período servindo de base para o acréscimo de informações, o que comprova que essa variação denominativa está sendo utilizada em prol de uma coesão do texto e para a progressão do tema. Talvez a ideia - equivocada, lógico, de que o estilo da escrita acadêmica deve ser livre de repetições, colabora para o uso dessas expressões referenciais, o que também aponta a importância da variação denominativa no uso de diferentes expressões referenciais.

No trecho a seguir, retirado de uma palestra proferida por um especialista em cana-de-açúcar, que é uma transcrição de uma das palestras do corpus, é possível observar como a progressão referencial é feita nos textos orais especializados de modo diferente do texto escrito, visto que a repetição, como afirmam Marcuschi e Koch (2015), é um recurso que pode ser explorado pelo especialista na produção do texto falado. É notória a ausência de expressões nominais variantes que deem informações sobre o referente, como é possível constatar no trecho que segue.

Mas tinha hora que a gente também não tinha condição de retirar, a cana-soca vinha e o fardo tava lá dentro, e isso impedia de a gente dar continuidade nos tratos da cana-soca. Uma adubação, um herbicida e isso daqui foi, nós tivemos um problema muito sério em Patá, de fitoticidade por conta dessa operação, a gente retardava a aplicação do herbicida na cana-soca, e todas as vezes que a gente entrava na área, a cana já estava brotada e mesmo assim a gente tinha que fazer a aplicação de herbicida. Então, dava uma fitoticidade muito grande de herbicida na cana-soca. Determinamos lá que, a partir de agora, o nosso recolhimento de palha vai ter que acontecer, no máximo, 10 dias após a colheita da cana. Então, a gente teve esse... tivemos que remodelar, nos planejar para que isso acontecesse. Depois de colhida, com 10 dias, esses fardos não poderiam estar mais ali dentro. Então, nós tínhamos a chance de fazer o trato na cana-soca, ainda com ela com pouca brotação, principalmente por conta do herbicida que era e a gente entendia como um retardador do incremento da produtividade. (Pale 1)

Nesse trecho, o especialista retoma o referente utilizando-se apenas de um tipo de variação morfossintática do termo (redução do sintagma nominal). $\mathrm{O}$ uso recorrente de uma denominação é previsível por conta da baixa densidade de variação lexical de alguns gêneros que têm a materialidade na fala, como a conferência, além de pela necessidade de apresentar um texto mais formal para o público que lhe ouve, que é predomi- 
nantemente formado por especialistas e cientistas da comunidade ( $O$ evento é específico para donos de culturas agrícola da cana). Isso é provado pela quase ausência de expressões referenciais definitórias, ou expressões que expliquem o conceito, para tratar do conceito cana-soca, o que dificultaria a compreensão de um leigo, que, geralmente, não é o público-alvo dos eventos acadêmicos ou de mercado do setor, revelando os modos e um gênero recorrente nessa comunidade, que são os simpósios empresariais, caracterizados por palestras e cursos técnicos exclusivos para os integrantes da comunidade de agrônomos que trabalham com a cana-de-açúcar. Isso confirma a hipótese de que o especialista, em um ambiente tão formal e dialogando com indivíduos com o mesmo nível de conhecimento, não se preocupa em definir ou explicar o conceito de que trata. No trecho do texto da palestra, o especialista recorre à denominação mais recorrente no meio acadêmico-industrial, com apenas uma variação morfossintática comum que não compromete a referência ao conceito.

Esses e outros elementos próprios do universo especializado ou da comunidade discursiva de especialistas em cana-de-açúcar mostram uma comunidade coesa e que tem práticas de linguagem próprias. Os gêneros utilizados por esses especialistas moldam a comunicação e identificam-na como uma comunidade com práticas semelhantes a outras comunidades científicas. Os dados de variação denominativa e conceitual podem ser evidenciados e, muitas vezes, explicados a partir de aspectos que não são puramente formalistas, mas funcionais: o contexto e o próprio modo de se organizar, comunicar e estar de uma comunidade de cientista também podem/devem ser elementos para a compreensão do universo discursivo especializado. Desse modo, os dados aqui mostram um caminho para a análise da variação terminológica, para além da forma e do número e explica o processo comunicativo das comunidades de especialistas, ou, nos termos de Swales (1990), a comunidade discursiva do setor da cana-de-açúcar.

\section{Últimas considerações}

As reflexões colocadas neste texto são parte de outras discussões maiores sobre o status da Terminologia e sobre o futuro de suas pesquisas e avanços teóricos. Não resta dúvida de que a disciplina precisa buscar diálogo tanto com a Linguística quanto com outros campos do conhecimento humano. Como foi discutido ao longo deste texto, a relação da Terminologia com as teorias do discurso e dos gêneros e com a Linguística Textual oferece importantes e promissores caminhos para a compreensão do universo especializado e sua cultura comunicativa dentro das diferentes comunidades de 
especialistas que configuram um universo especializado ou uma comunidade discursiva de especialistas.

Nesse sentido, a Terminologia precisa avançar para discussões em que sejam centrados o uso, o contexto comunicativo e as culturas dos universos que busca analisar e fazer com que seu objeto de estudos avance para além da análise atomista da unidade léxica. A proposta Swales de comunidade discursiva é importante elo entre a Terminologia e as discussões sobre a cultura acadêmica, científica e social das diferentes áreas do saber e do fazer humano. O conceito de Swales leva os estudos das comunidades acadêmicas a entender o texto a partir de sua complexidade da pragmática, da cultura e da comunicação em suas diferentes dimensões de comunidades científicas, tirando uma visão homogênea das áreas das ciências, que já vem sendo discutida há muito pela filosofia das ciências.

Os dados do universo da cana-de-açúcar demonstraram que a variação terminológica é uma realidade nesse universo e seu reconhecimento e estudo pode ser uma contribuição para os estudos da descrição das terminologias das diferentes áreas do saber e fazer humano. Nessa direção, por meio de um tratamento textual-discursivo, é possível analisar o fenômeno da variação terminológica denominativa e conceitual, demonstrando nuances da forma de se comunicar de cada cultura acadêmico-científica. A va- riação, nesse sentido, é vista em sua forma funcional, não apenas nas unidades lexicais do discurso. Em outras palavras, é necessário ver a variação como parte do discurso e não apenas do léxico.

A Terminologia, em comparação com outras áreas da Linguística, é um jovem campo de análises. Muito ainda se tem para explorar e achar sobre o universo comunicativo dos saberes especializados. Nesse sentido, a recepção de novas abordagens, olhares diferentes, para além da forma e do conteúdo, podem enriquecer ainda mais a Terminologia, fazendo com que ela colabore ainda mais com a comunicação não só das comunidades discursivas especializadas, mas também dos diferentes discursos que ocorrem na nossa sociedade.

Por fim, as teorias do texto e do discurso têm muito a colaborar assim como receber da Terminologia, sobretudo pelas diferentes discussões sobre o mesmo objeto de estudos: a comunicação nos ambientes acadêmico-científicos. 
The Specialized textual genders and the discursive community concept as elements of analysis
of the denominative variation
in terminology

\section{Abstract}

The text presents a set of reflections on the relationship between Terminology and other fields of Linguistics and how this relationship can contribute to the expansion of the discipline. Textual Linguistics and Theories of Genres and the text contribute to the discussion. In the last field a dialogue with the works of Swales (1990, 2016) on the notion of discursive community would be interesting. It is assumed that the analysis of phenomena studied by Terminology can be made from the dialog of Terminology with these fields of knowledge. The reflections presented here are made from the analysis of a diversified corpus with characteristics that are conditioned to the form of communication of specialists from a community of specialists in the sugarcane sector. The results show that many aspects of terminological variation can be understood from the treatment of data with theoretical reflections of the text and discourse present in Linguistics.

Keywords: Terminological Variation; specialized text and Genre; discoursive community

\section{Notas}

1 Todas as traduções feitas neste texto são sugestões de tradução feitas por seus signatários: Hoy en día la variación de los términos es un fenómeno perfectamente aceptado, y de hecho es un supuesto de base ya establecido para la investigación en terminología.

2 Terminologies as aggregates of terms, which represent the systems of concepts of the various subject fields, are the most important tools for: 1 . Systematization of knowledge (that is, conceptual classification for each scientific discipline). 2. Transfer of knowledge, skills, and technology. 3. Translation of scientific texts. 4. Formulation of subject information. 5. Retrieval of stored subject information (indexing languages, thesauri, classification).

3 La terminología puede formar parte de los signos del lenguaje natural e integrarse en el conocimiento del hablante, que es al mismo tempo hablante de una lengua y profesional de una materia.

4 Dentro da abordagem descritivista, existem inúmeras discussões e caminhos para a discussão dos fenômenos da comunicação especializada. Considerando os limites e os objetivos deste texto, serão focados apenas alguns, sem deixar de considerar a importância que essas outras discussões têm para a compreensão da comunicação em ambiente

5 Les texts savants saissisent et expriment le contenu savant, dont les unités sémantique dominantes sont les termes. Le term est une unité lexicale - ou son acception - définie dans les texts savants, où apparaissent ses occurrences intégrées dans le tessitu du text

6 el carácter de término lo activan en función de su uso en un contexto y situación adecuados.

7 Així doncs, sembla que la coincidència en l'ús de certs recursos lingüístics i en la similitud de la funció comunicativa proporciona una base per a la classificació dels textos especialitzats. Aquesta hipòtesi es veu reforçada per la diferenciació més o menys intuïtiva i pràctica dels tipus textuals, com ara llibre de text, obra de consulta, article, recensió, informe, crítica, carta comercial etc. 


\section{Referências}

BAHKTIN, M. Os gêneros do discurso. São Paulo: Editora 34, 2016.

BIASI-RODRIGUES, B.; ARAÚJO, J. C.; SOUZA, C. S. T. Análise de gêneros na abordagem de Swales: princípios teóricos e metodológicos. In: BIASI-RODRIGUES, B.; ARAÚJO, J. C.; SOUZA, C. S. T. (Org.). Gêneros textuais e comunidades discursivas: um diálogo com John Swales. Belo Horizonte: Autêntica, 2009. p. 17-32.

CABRÉ, M.T. Terminology: theory, methods and applications. Philadelphia/ Amsterdam: John Benjamins, 1998.

CABRÉ, M.T. La terminología: representación y comunicación. Elementos para una teoría de base comunicativa y otros artículos. Barcelona: Institut Universitari de Linguística Aplicada, 1999.

CABRÉ, M.T. Theories of terminology: their descriptions, prescriptions and explanation. Terminology, n. 9, v. 2, 163-199, 2003.

CIAPUSCIO, G. E. La terminologia desde el punto de vista textual: seleción, tratamiento y variación. Organon, v. 12, n.26, p. 1-15, 1998.

CIAPUSCIO, G. E. Textos especializados y terminología. Barcelona: IULA, 2003.

FELBER, Helmut. Basic principles and methods for the preparation of terminology standards. In. C. G. INTERRANTE AND F. J. HEYMANN (orgs). Standardization of Technical Terminology: Principles and Practices, ASTMSTP806. American Society for Testing and Materials, 1983, pp. 3-14.

FELBER, Helmut. Terminology Manual. Paris: UNESCO/ INFORTERM, 1984.

FINATTO, M. J. B; AZEREDO, S. Observações da tessitura do texto especializado são observações de/em terminologia? In. ISQUERDO, A. N.; FINATTO, M. J. B. As ciências do léxico: lexicologia, lexicografia e terminologia. Campo Grande / Porto Alegre: EdUFMS/ EDUFRGS, 2010, p.557-577.

FINATTO, M. J. B. Terminologia e Lingüística de Corpus: da Perspectiva Enunciativa aos Novos Enfoques do Texto Técnico-científico. Letras de Hoje, Porto Alegre, v.39, n.4, dezembro, 2004. p.97-106.

HOFFMAN, L. Textos e Termos por Lothar Hoffman. In M. J. B. FINATTO, \& L.

ZILIO (Ed.), Textos e Termos por Lothar Hoffman. Porto Alegre, RS: Palloti, 2015.

HOFFMAN, L. Llenguatges d' especialitat. Madrid: Universitat Pompeu Fabra, 1998.

FREIXA, Judith. La variació terminològica. Anàlisi de la variació denominativa en textos de diferent grau d'especialització de l'àrea de medi ambient. 397f. Tese (Doutorado em Linguística Aplicada). Universidade Pompeu Fabra, Instituto di Lingüística Aplicatta, 2002.

HEMAIS, B; BIASI-RODRIGUES, B. A proposta sociorretórica de John M. Swales para o estudo de gênero textuais. In. MAURER, J. L.; BONINI, Adair; MOTTA-ROTH, D. (Orgs). Gêneros: teorias, métodos, debates. São Paulo: Parábola, 2005.

$\mathrm{KOCH}$, Ingedore Villaça. Especificidade do texto falado. In. JUBRAN, Clécia Spinardi (org). A construção do texto falado. São Paulo: contexto, 2015, p.39-46.

KOCH, I. V. MARCUSCHI, L. A. Referenciação. In. JUBRAN, C. S. (org). A construção do texto falado: gramática do português culto falado no português. São Paulo: Contexto, 2015, p. 311-367.

KOCOUREK, R. Text et term. Meta: journal des traducteurs / Meta: Translators' Journal, vol. $36, \mathrm{n}^{\circ} 1,1991$, p. 71-76.

KRIEGER, Maria da Graça; FINATTO, M. J. B. Introdução à Terminologia. $2^{\mathrm{a}}$ ed. São Paulo: Contexto, 2016. 
SERRA, L. H. A variação denominativa no discurso especializado da cana-de-açúcar no Brasil: uma pesquisa sobre a variação funcional. Tese (Doutoramento em Letras - Filologia e Língua Portuguesa). 2019. 150fls. Faculdade de Filosofia, Letras e Ciências Humanas, Programa de Pós-graduação em Filologia e Língua Portuguesa, 2019.

SERRA, L H. A variação denominativa no discurso especializado do universo da cana-de-açúcar: a pertinência de dados orais na pesquisa terminológica. A cor das Letras (UEFS), v. 20, p. 192-203, 2019a.

SWALES, J. M. Genre analysis: English in academic and research settings. Cambridge: Cambridge University Press, 1990.

SWALES, J. M. Reflections on concept of discourse community. Asp. v.69, p. 7-19, 2016.

WÜSTER, Eugen. Introducción a la teoría general de la terminología y a la lexicografía terminológica. Tradução de Anne-Cécile Nokerman. Barcelona: IULA, 1998 